\title{
MRI assessment of treatment response
}

\author{
Ann D King \\ From International Cancer Imaging Society Meeting and 15th Annual Teaching Course (ICIS 2015) \\ London, UK. 5-7 October 2015
}

Locoregional failure occurs in approximately $25-50 \%$ of patients with head and neck squamous cell carcinoma (HNSCC), who are treated with chemoradiotherapy (CRT). Timely identification of treatment failure allows salvage surgery to be undertaken. Imaging the posttreatment neck therefore has an important role for the early identification of a residual/recurrent tumours while also preventing unnecessary biopsies or surgery in patients with expected post-treatment changes. This lecture will concentrate on the post CRT evaluation of primary and nodal sites in patients with HNSCC, using morphological assessment by MRI.

MRI assessment of the post treatment primary tumour bed is based on CT criteria and can be divided into (1) expected post treatment changes (low risk); (2) focal mass $<1 \mathrm{~cm}$ or asymmetry (indeterminate risk); (3) focal mass $\geq 1 \mathrm{~cm}$ (high risk). In addition MRI signal intensity can provide further information. Residual/recurrent tumours tend to have the same signal intensity as untreated tumours on all sequences, and in this regard the T2 weighted images are valuable in distinguishing tumour (intermediate signal intensity) from scar tissue (low signal intensity) and inflammation (high signal intensity). However, there may still be some overlap in the appearance of post treatment change and tumour.

The assessment of nodal response can be even more problematic, especially in the early post-treatment period. Reported morphological criteria for identifying nodal treatment response vary but most frequently nodal control is based on size $(<1-1.5 \mathrm{~cm})$; \% size reduction $(>75 \%-90 \%)$; absence of focal abnormalities such as necrosis; absence of extranodal neoplastic spread (ENS). These criteria are often combined and report high NPVs, valuable for excluding residual malignant nodes, but the PPVs are low. The poor diagnostic performance of these morphologic criteria is partly because necrosis and ENS are inaccurate signs for residual nodal cancer, and their presence reduces the accuracy of size measurements. Of note necrotic sterile nodes often take longer to decrease in size than solid sterile nodes.

Interactive clinical cases of primary and nodal HNSCC will be used to illustrate the expected post treatment findings, residual/recurrent tumours, and indeterminate findings that cause a diagnostic dilemma. DWI will also be illustrated and there will be a brief comparison of MRI and FDG PET-CT.

\section{Published: 2 October 2015}

\section{References}

1. Dillion WP, Mills CM, Kjos B, De Groot J, Brant-Zawadzki M: Magnetic resonance imaging of the nasophaynx. Radiology 1984, 152:731-738.

2. Ljumanovic R, Langendijk JA, Hoekstra OS, Knol DL, Leemans CR, Castelijns JA: Pre-and post-radiotherapy MRI results as a predictive model for response in laryngeal carcinoma. Eur Radiol 2008, 18:2231-2240.

3. Chen YH, Jian JJM, Chan KY, Tsai SY, Cheng SH, Yen KCL, Cheng JCH: Definitive chemoirradiation for resectable head and neck cancer: treatment outcome and prognostic significance of MRI findings. The British Journal of Radiology 2008, 81:490-498.

4. Lell M, Baum U, Greess H, Nömayr A, Nkenke E, Koester M, Lenz M, Bautz W Head and neck tumours: imaging recurrent tumor and post-therapeutic changes with CT and MRI. European Journal of Radiology 2000, 33:239-247.

5. de Bree R, van der Putten L, Brouwer J, Castelijns JA, Hoekstra OS, Leemans CR: Detection of locoregional recurrent head and neck cancer after (chemo) radiotherapy using modern imaging. Oral Oncol 2009, 45:386-393.

6. Pameijer FA, Hermans R, Mancuso AA, et al: Pre-and post-radiotherapy computed tomography in laryngeal cancer: imaging-based prediction of local failure. Int J Radiation Oncology Biol. Phys 1999, 45:359-366.

7. King AD, Keung CK, Yu KH, Mo FK, Bhatia KS, Yeung DK, Tse GM, Vlantis AC, Ahuja AT: T2-weighted MR imaging early after chemoradiotherapy to evaluate treatment response in head and neck squamous cell carcinoma. AJNR AM J Neuroradiol 2013, 34:1237-1241.

8. Liauw SL, Mancuso AA, Amdur RJ, Morris CG, Villaret DB, Werning JW, Mendenhall WM: Postradiotherapy neck dissection of lymph node positive head and neck cancer: the use of computed tomography to manage the neck. Journal of Clinical Oncology 2006, 24:1421-1427.

9. Labadie RF, Yarbrough WG, Weissler MC, Pillsbury HC, Mukherji SK: Nodal volume reduction after concurrent chemo-and radiotherapy: correlation between initial CT and histopathologic findings. AJNR Am J Neuroradiol 2000, 21:310-314.

doi:10.1186/1470-7330-15-S1-O26

Cite this article as: King: MRI assessment of treatment response. Cancer Imaging 2015 15(Suppl 1):O26. 